\title{
Puberty and menstruation knowledge among young adolescents in low- and middle-income countries: a scoping review
}

\author{
Ernestina Coast ${ }^{1}$ (D) Samantha R. Lattof ${ }^{2}$ (D) $\cdot$ Joe Strong $^{2}$
}

Received: 16 April 2018/Revised: 12 January 2019/Accepted: 18 January 2019/Published online: 10 February 2019

(C) The Author(s) 2019

\begin{abstract}
Objectives This study presents a scoping review of evidence relating to knowledge and experiences of puberty and menstruation among females aged 10-14 years in low- and middle-income countries.

Methods Forty-four items from 12 countries were identified from a systematic scoping review and screening of 8083 items. Included studies were quality assessed.

Results A majority (40/44) of studies used school-based samples, and fifteen studies reported on interventions. Girls had inadequate knowledge about menstruation; menarche as a trigger for girls learning about menstruation was common. Adolescents struggled with menstrual hygiene. Negative emotions were associated with menarche and menstrual management. A minority of studies dealt explicitly with puberty. Most girls obtained information about menstruation and/or puberty from their mothers, although mothers were not necessarily girls' preferred source for learning about these topics. Conclusions Young adolescent girls are under-prepared for puberty and menstruation. Predominantly school-based studies mean we know little about young out-of-school adolescents. The evidence base lags behind the rise in interest from practitioners as well as the development (and evaluation) of puberty and/or menstruation interventions.
\end{abstract}

Keywords Puberty $\cdot$ Menarche $\cdot$ Menstruation $\cdot$ Adolescence $\cdot$ Scoping review

\section{Introduction}

More than a quarter (26\%) of the world's population is female and of reproductive age, and most of them will menstruate monthly. Pre-menarche they will have begun puberty, involving physical, psychological, and cognitive transitions, lasting for most of the second decade of life. Puberty onset or menarche may define a time when girls' roles change (Dolan et al. 2014; Mason et al. 2013; Mmari et al. 2016), including increased adult roles; changes in

This article is part of the special issue "Adolescent transitions".

Electronic supplementary material The online version of this article (https://doi.org/10.1007/s00038-019-01209-0) contains supplementary material, which is available to authorized users.

Ernestina Coast

e.coast@1se.ac.uk

1 Department of International Development, London School of Economics and Political Science, London, UK

2 Department of Social Policy, London School of Economics and Political Science, London, UK dress/deportment/behaviour; cessation or interruption of schooling; and mobility restrictions. How puberty is presented and experienced by girls and boys is different (Shaikh and Rahim 2006; Tasnim et al. 2009), with a "dominant narrative" of puberty as "shameful for girls while in contrast celebrating male virility" (UNESCO 2014, p. 11). The consequences of not knowing about puberty and menstruation include not understanding or being prepared for future fertility implications, for example. Among adolescent girls, fear and shame of menstruation are frequent themes that emerge both in countryspecific studies and global reviews (Hennegan and Montgomery 2016; Mason et al. 2013; Sommer et al. 2015). The objective of this scoping review is to systematically map the range and quality of studies on knowledge and experiences of puberty and/or menstruation among young adolescents in low- and middle-income countries (LMICs).

In LMICs interventions and research tend to focus on older (15-19 years) adolescents (Igras et al. 2014). Early or young adolescence-10-14 years-incorporates the ages at which most girls begin puberty. Education about puberty is a "crucial" (UNESCO 2014) aspect of adolescent 
development. Recent guidance about puberty and menstruation education in LMICs (Haver and Long n.d.; House et al. 2012) has been accompanied by some countries developing national guidelines (MDWS 2015). These developments reflect growing understanding of the importance of puberty, and guidance documents include the need for information to be: age appropriate; culturally relevant; taught to both boys and girls; and deal with the software (e.g. knowledge) and hardware (e.g. absorbents, disposal) of menstruation.

Evidence documents the impact of menstrual hygiene management (MHM) on education, with problems of MHM affecting girls' school attendance (WHO and UNICEF 2013). The management of puberty and menstruation might impact negatively on psychosocial well-being (e.g. stress, fear, embarrassment, shame). Parents may withdraw a daughter from school because puberty and menstruation are associated with reproduction and/or marriage, and/or concern about potential sexual advances by male students or teachers (Kirk and Sommer 2006).

Four systematic reviews reflect interest in menstruation as a research and/or intervention topic in LMICs; none focus exclusively on young adolescents or deal with puberty. Two reviews included menstruating females of all ages (Hennegan and Montgomery 2016; Sumpter and Torondel 2013), one included all female adolescents aged 10-19 (Chandra-Mouli and Patel 2017) and one included adolescent girls in India (van Eijk et al. 2016). Sumpter and Torondel's systematic review focused on the health and social consequences of MHM (Sumpter and Torondel 2013). All four reviews focused on menarche and menstruation, separating it from broader pubertal transitions. The studies included in all four reviews were heterogeneous with associated risks of bias, and most included studies were deemed low quality across all four reviews. Chandra-Mouli and Patel noted varied design and context in their included studies, with inconsistencies in measuring key concepts (e.g. knowledge of menstruation), weaknesses around sample sizes, and high risks of bias in randomisation processes (Chandra-Mouli and Patel 2017). Inconsistently measured outcomes and an inability to draw synthesised conclusions were highlighted by two reviews (Hennegan and Montgomery 2016; van Eijk et al. 2016).

By situating menarche and menstruation within a broader pubertal transition (e.g. pubertal growth spurt, thelarche), our study extends beyond these reviews to incorporate young adolescent girls' knowledge and experiences of puberty in LMICs. By combining puberty and menarche/menstruation, we draw attention to the ways in which two linked-but distinct-transitions and experiences are dealt with in the evidence base for young adolescents. By focusing on adolescents aged 10-14 years, our scoping review highlights the experiences of a critical age group that is likely to be experiencing, or about to experience, these transitions.

\section{Methods}

We took a systematic, transparent, and reproducible approach to searching and including evidence in our scoping review in order to describe as widely as possible all of the relevant literature without, for example, limiting inclusion by study type or quality (Grant and Booth 2009; The Joanna Briggs Institute 2015). Our review, which used Arksey and O'Malley's framework (Arksey and O'Malley 2005), focuses on evidence relating to early adolescent (aged 10-14 years) girls' knowledge about and experiences of puberty and menstruation in LMICs (Fig. 1).

Studies on any population in LMICs were considered, using the World Bank Country and Lending Groups classification (World Bank 2016). Peer-reviewed journal articles and (non-peer-reviewed) grey literature, including reports, books or book chapters, whether in print or online, were eligible. For inclusion, studies must have:

- Included evidence relating to adolescent females aged 10-14 years. Studies including females outside this age range (e.g. ages 10-19 years) were included if the population's mean age was between 10 and 14 years

- Stated as an outcome or aim to increase, or measured as an outcome, 10-14-year-old adolescent females' knowledge of puberty or menstruation (including menstrual hygiene)

- Been published in English

- Been published between 1/1/2006 and 30/10/2017

- Measured at least one of these outcomes: knowledge of menstruation; menstrual hygiene practices; knowledge of puberty; attitudes, myths, and/or perceptions of menstruation/puberty; experiences of menstruation/puberty; or, sources of information about menstruation/ puberty.

Quality was not a criterion for inclusion; we sought breadth and depth in our search (Khalil et al. 2016). Multiple references based on the same sample were not excluded in order to maximise the coverage of our review. By taking this approach - a variety of sources and a mixed body of evidence (type and methodology)—our scoping review generates an "overview of what is currently known and draws attention to areas where there are prominent knowledge gaps" (Davis et al. 2009, p. 1396). It establishes the extent of available evidence and how the research has been conducted (The Joanna Briggs Institute 2015). 
Fig. 1 Populations, interventions, comparators, outcomes, and setting criteria for inclusion

\begin{tabular}{|l|l|}
\hline Participants & $\begin{array}{l}\text { - Adolescent girls aged 10-14 years or female } \\
\text { populations in which the mean age was between } \\
10 \text { and } 14 \text { years }\end{array}$ \\
\hline ComparisOn & $\begin{array}{l}\text { - Knowledge of puberty and menstruation } \\
\text { (including menstrual hygiene) }\end{array}$ \\
\hline Setting & $\begin{array}{l}\text { - None } \\
\text { - Knowledge of puberty } \\
\text { - Knowledge of menstruation } \\
\text { Antitudes, myths and/or perceptions of } \\
\text { menstruation or puberty } \\
\text { - Sources of information about menstruation or } \\
\text { puberty } \\
\text { - Experiences of menstruation or puberty } \\
\text { - Menstrual hygiene practices }\end{array}$ \\
\hline
\end{tabular}

Searches and application of inclusion criteria were conducted using an approach informed by the Preferred Reporting Items for Systematic Reviews and Meta-Analyses (PRISMA) flow approach (PRISMA 2017). Four sets of search terms (Table 1) were used in combination. Searches were not constrained by geographic location; studies focusing only on high-income countries were excluded at title and abstract (TIAB) screening. Search terms were tested in three databases (PubMed, ISI Web of Science (WoS), ScienceDirect) and crosschecked with medical subject headings dictionaries. Search term combinations were adapted to each database (e.g. wildcards, truncations). We systematically searched five electronic databases (PubMed, ISI WoS, ScienceDirect, JStor, Google Scholar) and one website (R4D).

This search generated 9773 items for screening. After duplicate removal, the 8083 remaining items were screened for inclusion on the basis of TIAB. We determined eligibility of all items, and unclear items were discussed. Where exclusion could not be determined on the basis of TIAB SRL and JS screened the full text. Decisions were made in favour of an inclusive approach where questions remained. Forty-four items were included in the scoping review. We were unable to retrieve two items for full-text screening (Bawono 2017; Hyang-Mi et al. 2006) (Fig. 2), as the items were unavailable from interlibrary loan or directly from the authors

EC, SRL, and JS extracted data into SPSS for a randomly selected study to assure quality in data extraction.
SRL and JS extracted data from all other studies. We present the results narratively, organised thematically. Included studies were quality assessed in duplicate [EC, SRL, and JS] using tools for quantitative and qualitative studies (EPHPP 2010; Solnes Miltenburg et al. 2013; Walsh and Downe 2006). The inclusion of quality assessment in a scoping review has been identified as useful for identifying gaps in the evidence base (Pham et al. 2014). As a scoping review, meta-analysis or meta-synthesis was inappropriate because of the heterogeneity of studies, populations, and outcomes.

Method limitations may have resulted in missed relevant items, specifically non-English items and those published outside of our time period. Since the searches were limited to six online sources, we may have missed relevant grey literature. The possibility is high that we missed some relevant in-service reports that were not intended or prepared for wider circulation. As an under-researched field, but one receiving growing attention, it is likely that evidence relating to young adolescents exists in the unpublished or grey literature (IRH 2011, 2013a, b, 2015a). As Sumpter et al. note, "there is a strong possibility that the best knowledge lies in the hands of those implementing programs" (Sumpter and Torondel 2013). Finally, despite attempts, we were unable to retrieve two items (Bawono 2017; Hyang-Mi et al. 2006) for screening that may have been eligible for inclusion. 
Table 1 Search terms, their combinations, and database application

\begin{tabular}{|c|c|c|c|c|c|c|}
\hline \multicolumn{2}{|l|}{ All 6 databases } & \multicolumn{2}{|l|}{ All 6 databases } & \multicolumn{2}{|l|}{$\begin{array}{l}\text { PubMed, ISI Web of Science, } \\
\text { ScienceDirect }\end{array}$} & \multirow{2}{*}{$\begin{array}{l}\text { PubMed, ISI Web of Science, } \\
\text { ScienceDirect } \\
\text { 4. Intervention/study type terms }\end{array}$} \\
\hline $\begin{array}{l}\text { 1. Adolescent } \\
\text { terms }\end{array}$ & AND & $\begin{array}{l}\text { 2. Puberty and } \\
\text { menstruation terms }\end{array}$ & AND & $\begin{array}{l}\text { 3. Knowledge and understanding } \\
\text { terms }\end{array}$ & AND & \\
\hline adolescen* & & puberty & & know* & & arrangement* \\
\hline girl* $^{*}$ & & pubescen* & & understand* & & evaluat* \\
\hline teenage* & & sexual maturity & & manage* & & initiative* \\
\hline youth* & & catamenia & & learn* & & intervention* \\
\hline \multirow[t]{11}{*}{ pre-adolescen* } & & menstrua* & & apprehen* & & model* \\
\hline & & menarch* & & comprehensi* & & package* \\
\hline & & mense* & & educat* & & pilot* \\
\hline & & & & aware* & & program* \\
\hline & & & & familiar* & & project* \\
\hline & & & & proficien* & & provision* \\
\hline & & & & & & regime* \\
\hline & & & & & & scheme* \\
\hline & & & & & & strateg* \\
\hline & & & & & & trial* \\
\hline & & & & & & approach* \\
\hline
\end{tabular}

*Refers to truncated word roots in order to capture multiple derivations, e.g. adolescen* will capture adolescent, adolescents, adolescence, etc (adolescen* OR girl* OR teenage* OR youth* OR pre-adolescen*) AND (puberty OR pubescen* OR "sexual maturity" OR menstrua* OR menarch* OR mense* OR catamenia) AND (know* OR understand* OR manage* OR learn* OR apprehen* OR comprehensi* OR educat* OR aware* OR familiar* OR proficien*) AND (arrangement* OR evaluat* OR initiative* OR intervention* OR model* OR package* OR pilot* OR program* OR project* OR provision* OR regime* OR scheme* OR strateg* OR trial* OR approach*)

\section{Results}

Forty-four studies, from twelve countries, met all of the inclusion criteria (Supplementary Material, Table 1). The majority (30/44) were descriptive cross-sectional studies, with eight using a pre-post-test design and six randomised controlled trials (RCT). Most studies (40/44) used schoolbased samples (Table 2). Fifteen studies reported interventions ( Supplementary Material, Table 2), with interventions in Iran $(n=5)$ and India $(n=4)$ accounting for more than half of all intervention studies. The quality of included studies was weak (36/44); two studies were strong quality (Mason et al. 2013; Valizadeh et al. 2017) and six studies were of moderate quality (Tables 3,4 ). We organise our results using the set of outcomes specified in our inclusion criteria, beginning with knowledge (and sources) of puberty and menstruation, then attitudes, myths, and/or perceptions before turning to experiences and practices.

\section{Knowledge of puberty}

Few (9/44) studies address knowledge of puberty, and none include early sexual feelings, sexual development, sexuality, or related topics. These findings may reflect an elision by researchers and/or respondents of puberty with menstruation for girls. However, puberty is a broad set of changes, of which menstruation is one. One study, from Turkey, provided unambiguous definition of what the authors defined as "normal" puberty development (Isguven et al. 2015). In this survey of schoolgirls, three quarters (75.2\%) self-identified as being knowledgeable about puberty and answered detailed questions about the first symptom of puberty (breast development, pubic and axillary hair, acne).

A study from Nigeria reported attitudes of mothers towards teaching their daughters about a variety of sexual and reproductive health issues. Most mothers (88.6\%) agreed that adolescent girls should be informed about body changed at puberty (Iliyasu et al. 2012). In mothers' narratives about discussions with their daughters, issues of puberty were bound up with issues relating to appearance, dress, use of cosmetics, courtship, sexuality and sexual behaviour. A comparative study of Nigeria and Kenya found that female adolescents were more likely to mention breast development than menstruation as associated with puberty. Adolescents went to great lengths to try to hide their bodily changes from others, including parents (Bello et al. 2017).

An Iranian study evaluated an educational program about puberty health on schoolgirls' knowledge (Moodi 
Fig. 2 Search and screening results for ISI Web of Science (WoS), JSTOR, Department for International Development Research for Development (DFID R4D), Google Scholar, PubMed, Science Direct

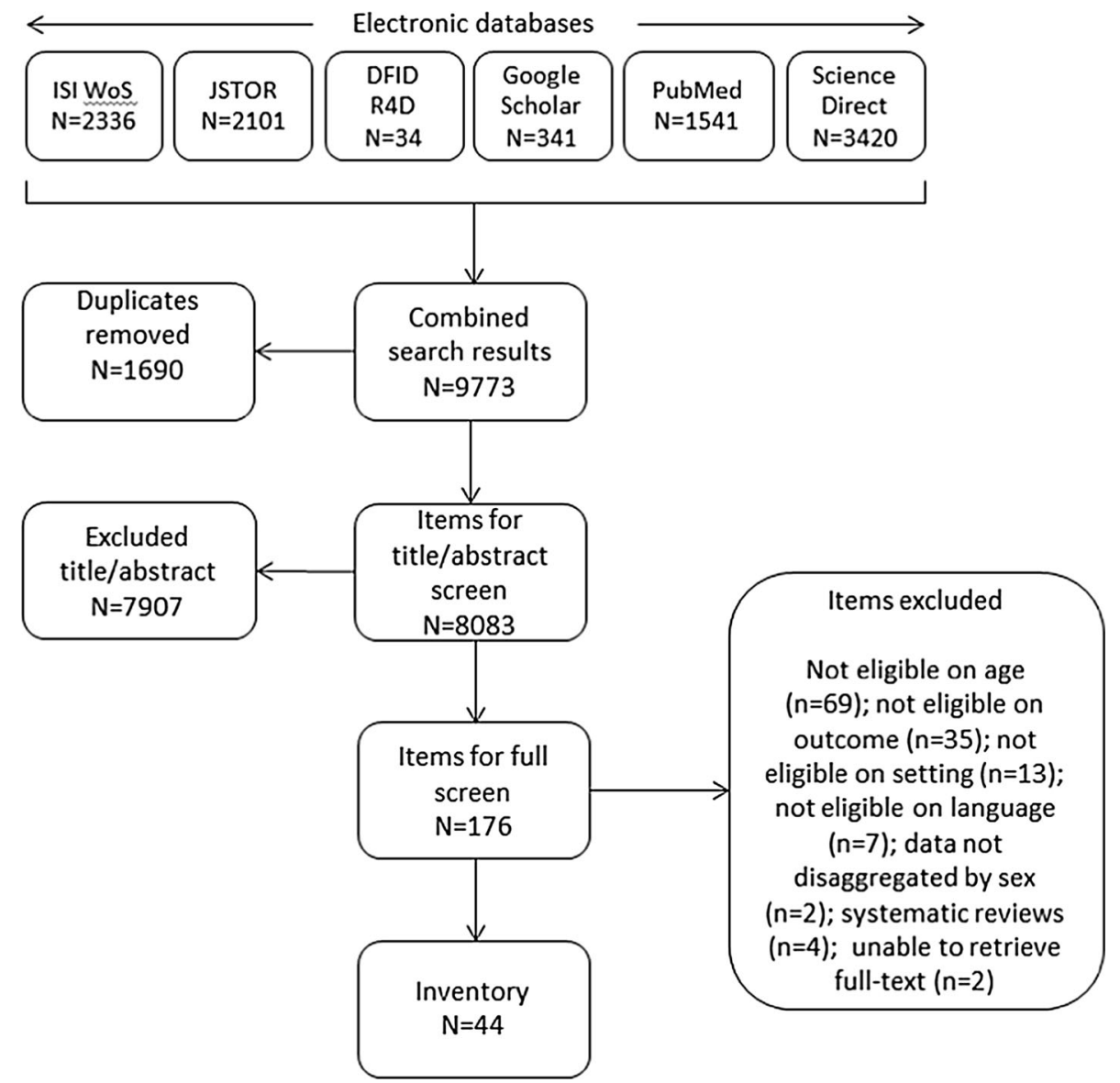

et al. 2013). The study reported a significant difference between pre- and post-intervention results $(p<0.001)$, although there is little detail about either the intervention content or how knowledge scores were developed. The authors noted that due to shame and modesty, pre-pubertal girls tended not to discuss puberty with their mother. Though multiple studies from Iran focused on "puberty health" in their aims, the content frequently reported girls' knowledge and experience of menstruation (Afsari et al. 2017a; Kheirollahi et al. 2017; Saghi et al. 2016; Valizadeh et al. 2017). This implies a potential elision by researchers of puberty with menstruation.

\section{Knowledge of menstruation}

Knowledge of menstruation was a frequently included outcome (25/44). Across studies, girls have inadequate knowledge about menstruation and low levels of knowledge pre-menarche. A study from Bangladesh reported that $64 \%$ of girls were "reaching menarche in fear" (Bosch et al. 2008). In India, $60.3 \%$ girls did not know about menstruation prior to menarche, and they reported a poor understanding of the source and pathway of menstrual blood (Shah et al. 2013). Menarche as a trigger for girls learning about menstruation was common (Iliyasu et al. 2012; Mason et al. 2013).

Some studies framed questions in terms of "normal" age at menarche, "normal" duration of menstrual cycle, or "normal" flow. With one exception (Isguven et al. 2015), however, it is unclear how researchers define "normal". Some studies did not report whether the response categories in surveys were closed or open ended (with post hoc coding). In Nepal, responses to the question "what is menstruation?" were reported using three categories (physiological, pathological, curse); it is unclear whether these were closed response categories, and if they were, how respondents understood the meanings (Adhikari et al. 2007).

Whilst most studies used survey questions, a study from India conducted a content analysis of questions about menstruation posed by girls aged 9-13 years, such as "Do we become infertile if our sanitary pad that is left in open is eaten or sniffed by a snake?" (Chothe et al. 2014). These questions provided culturally and contextually relevant insights into young adolescents' understandings of menstruation. However, teachers were present during these question-and-answer sessions, potentially influencing girls' questions. 
Table 2 Characteristics of included studies

\begin{tabular}{ll}
\hline Country & India (17) \\
Iran (7) & Kenya (4) \\
Nigeria (4) \\
Bangladesh (3) \\
Mexico (2) \\
Nepal (2) \\
Uganda (2) \\
China (1) \\
Jordan (1) \\
Pakistan (1) \\
Turkey (1) \\
Yes (15) \\
Knowledge of menstruation (25) \\
Menstrual hygiene practices (22) \\
Knowledge of puberty (9) \\
Attitudes, myths, and/or perceptions about menstruation (16) \\
Experiences of menstruation (26)/puberty (1) \\
Sources of information about menstruation (17)/puberty (4) \\
Descriptive cross-sectional (quantitative) (23) \\
Descriptive cross-sectional (qualitative) (5) \\
Descriptive cross-sectional (mixed methods) (2) \\
Pre-post-test (8) \\
RCT (6) \\
In-school (40) \\
In-school and out-of-school (1) \\
Community-based sample (3) \\
Study type & \\
Oudy population & Deasure
\end{tabular}

Three studies examined interventions addressing knowledge of menstruation, all using a pre-post-test design (Haque et al. 2014; Shah et al. 2013; Sharma et al. 2015). An intervention in Bangladesh involved training schoolgirls on menstrual hygiene and reported significant $(p<$ 0.001 ) impacts on some aspects of knowledge (e.g. menstruation blood is impure) but not others (e.g. cause of menstruation, origin of menstrual blood). This intervention study reported that recruiting female research assistants helped participants feel more comfortable discussing menstruation (Haque et al. 2014). Levels of knowledge about the biological (as opposed to hygiene) content of the intervention were not significantly improved. The authors posed a questionnaire during group discussions, raising issues about priming effects.

\section{Attitudes, myths, and/or perceptions about menstruation}

Sixteen studies addressed fear, shame, secrecy, sexual vulnerability, positive/negative attitudes, and sociocultural constraints rooted in myths and taboos. Kenyan girls perceived pubescent, menstruating girls to be increasingly vulnerable to marriage, sexual advances, and abuse (Mason et al. 2013). A study in Bangladesh reported that $17 \%$ of girls asked questions about menstruation that researchers classified as myths and taboos (Bosch et al. 2008). Comparative analysis from India showed higher negative attitudes towards menarche in rural compared to urban areas (Anbumalar and Sasirekha 2016). A phenomenological analysis from Jordan found that adolescent girls considered talking about menarche to be "socially unacceptable" and "rude" (Al Omari et al. 2016).

Two studies measured girls' attitudes towards menstruation in Bangladesh and Mexico. Upon reaching menarche in Bangladesh, nearly two-thirds (64\%) of girls reported feeling scared (Bosch et al. 2008). Mexican schoolgirls were significantly $(p<0.0001)$ more likely to have negative feelings or feelings of secrecy about menstruation than they were to have positive feelings. Girls who were more knowledgeable and felt prepared for menstruation felt less negative and secretive (Marván and Molina-Abolnik 2012). A software intervention in China reported a statistically significant decrease in attitudes that menstruation was "debilitating and bothersome" in the group that received an educational intervention (Su and Lindell 2016). 
Table 3 Summary of quality assessments for quantitative studies

\begin{tabular}{|c|c|c|c|c|c|c|c|}
\hline References & $\begin{array}{l}\text { Selection } \\
\text { bias }\end{array}$ & Design & Confounders & Blinding & $\begin{array}{l}\text { Data collection } \\
\text { methods }\end{array}$ & Withdrawal/dropouts & $\begin{array}{l}\text { Overall study } \\
\text { quality }\end{array}$ \\
\hline Adhikari et al. (2007) & $* * *$ & $* * *$ & - & $* *$ & $* * *$ & $* * *$ & Weak \\
\hline Alam et al. (2017) & $* *$ & $* * *$ & $* * *$ & $* * *$ & $* * *$ & - & Weak \\
\hline $\begin{array}{l}\text { Anbumalar and Sasirekha } \\
\text { (2016) }\end{array}$ & $* *$ & $* * *$ & $* * *$ & $* * *$ & $* * *$ & - & Weak \\
\hline Afsari et al. (2017a) & $* *$ & $*$ & * & ** & ** & $*$ & Moderate \\
\hline Afsari et al. (2017b) & $* *$ & $* * *$ & $* * *$ & $* * *$ & $* *$ & - & Weak \\
\hline Bosch et al. (2008) & $* * *$ & $* * *$ & - & $* *$ & $* * *$ & $* *$ & Weak \\
\hline Dabade and Dabade (2017) & $* *$ & $* * *$ & $* * *$ & $* * *$ & $* * *$ & - & Weak \\
\hline Djalalinia et al. (2012) & $* * *$ & $*$ & $* * *$ & $* *$ & $*$ & $*$ & Weak \\
\hline Fazio et al. (2017) & $* *$ & $* * *$ & $* * *$ & $* *$ & $* *$ & $* * *$ & Weak \\
\hline Haque et al. (2014) & $* *$ & $* * *$ & - & $* * *$ & $* *$ & $*$ & Weak \\
\hline Hennegan et al. (2016) & $* *$ & $*$ & $* * *$ & $* * *$ & $* * *$ & $* * *$ & Weak \\
\hline Hossain et al. (2017) & $* *$ & $* * *$ & $* * *$ & $* * *$ & $* * *$ & - & Weak \\
\hline Iliyasu et al. (2012) & $*$ & $* * *$ & - & $* *$ & $* * *$ & $*$ & Weak \\
\hline Isguven et al. (2015) & $* *$ & $* * *$ & - & $* *$ & $* * *$ & $*$ & Weak \\
\hline Jena et al. (2017a) & $* *$ & $* * *$ & $* * *$ & $* * *$ & $* * *$ & - & Weak \\
\hline Jena et al. (2017b) & $* *$ & $* * *$ & $* * *$ & $* *$ & $* * *$ & $*$ & Weak \\
\hline Kapadia-Kundu et al. (2014) & $* *$ & $*$ & $*$ & $* *$ & $* * *$ & $*$ & Moderate \\
\hline Kheirollahi et al. (2017) & $* *$ & $*$ & $* * *$ & $* *$ & $*$ & $* * *$ & Weak \\
\hline Kumar et al. (2016) & $* *$ & $* * *$ & $* * *$ & $* * *$ & $* * *$ & - & Weak \\
\hline $\begin{array}{l}\text { Marván and Molina-Abolnik } \\
\text { (2012) }\end{array}$ & $* *$ & $* * *$ & - & $* *$ & $* * *$ & $*$ & Weak \\
\hline $\begin{array}{l}\text { Marván and Alcalá-Herrera } \\
\text { (2014) }\end{array}$ & $* *$ & $* * *$ & - & $* *$ & $* * *$ & $*$ & Weak \\
\hline Mishra et al. (2017) & $* *$ & $* * *$ & $* * *$ & $* *$ & $* * *$ & $*$ & Weak \\
\hline Montgomery et al. (2016) & $* *$ & $*$ & $*$ & $* * *$ & $* *$ & $* * *$ & Weak \\
\hline Moodi et al. (2013) & $* * *$ & $* *$ & * & $* * *$ & $* *$ & $*$ & Weak \\
\hline Mumtaz and Ansari (2016) & $* *$ & $*$ & $* * *$ & $* *$ & $* *$ & $* *$ & Moderate \\
\hline Nagaraj and Konapur (2016) & $* *$ & $* * *$ & $* * *$ & $* * *$ & $* *$ & - & Weak \\
\hline Phillips-Howard et al. (2016) & $* *$ & $*$ & $* * *$ & $* *$ & $* *$ & $*$ & Moderate \\
\hline Pratibha et al. (2016) & $* *$ & $* * *$ & $* * *$ & $* *$ & *** & $*$ & Weak \\
\hline Ramachandra et al. (2016) & $* *$ & $* * *$ & $* * *$ & $* *$ & $* * *$ & - & Weak \\
\hline Saghi et al. (2016) & $* *$ & $*$ & $* * *$ & $* *$ & $*$ & $* * *$ & Weak \\
\hline Shah et al. (2013) & $* *$ & $* * *$ & - & $* *$ & $* * *$ & $*$ & Weak \\
\hline Sharma et al. (2015) & $* * *$ & $* *$ & $* * *$ & $* *$ & $*$ & $*$ & Weak \\
\hline Sharma et al. (2016) & $* *$ & $* * *$ & $* * *$ & $* *$ & $* * *$ & - & Weak \\
\hline Sharma and Moktan (2017) & $* *$ & $* * *$ & $* * *$ & $* *$ & $* *$ & - & Weak \\
\hline Shoor (2017) & $* *$ & $* * *$ & $* * *$ & $* * *$ & $* * *$ & - & Weak \\
\hline Sridhar and Gauthami (2017) & $* *$ & $* * *$ & $* * *$ & $* *$ & $* * *$ & - & Weak \\
\hline Su and Lindell (2016) & $* *$ & $* * *$ & $* * *$ & $* *$ & $*$ & $* *$ & Weak \\
\hline Um et al. (2010) & $* *$ & $* * *$ & - & $* *$ & *** & $*$ & Weak \\
\hline Valizadeh et al. (2017) & * & $*$ & * & * & ** & $*$ & Strong \\
\hline
\end{tabular}

Key [scores based on EPHPP (2010)]

- Unclear/not specified

- Not relevant to article

*Strong

**Moderate

$* * *$ Weak 
Table 4 Summary of quality assessment for qualitative studies

\begin{tabular}{|c|c|c|c|c|c|c|c|}
\hline References & Scope and purpose & Design & Sampling strategy & Analysis & Interpretation & Reflexivity & Overall \\
\hline Agofure and Iyama (2016) & $* *$ & $* * *$ & $* *$ & $* * *$ & $* * *$ & $* * *$ & Moderate \\
\hline Al Omari et al. (2016) & $* *$ & $* *$ & $*$ & $*$ & $* *$ & $* * *$ & Weak \\
\hline Bello et al. (2017) & $* *$ & $*$ & $*$ & $*$ & $*$ & $* * *$ & Moderate \\
\hline Chothe et al. (2014) & $* *$ & $*$ & $* * *$ & $* *$ & $* * *$ & $* *$ & Weak \\
\hline Mason et al. (2013) & $*$ & $*$ & $*$ & * & $*$ & $* *$ & Strong \\
\hline
\end{tabular}

Key [Based on Walsh and Downe (2006)]

*Strong

**Moderate

$* * *$ Weak

\section{Sources of information about menstruation/ puberty}

Most studies revealed that girls obtained information about menstruation and/or puberty from their mothers. Mothers, however, were not necessarily girls' preferred source of information. Some studies asked adolescents whom they thought should be teaching them. In Nepal, most girls (65.3\%) preferred learning from a course book (Adhikari et al. 2007). In Turkey, when schoolgirls were asked who should provide education about puberty, the majority reported health professionals $(54.4 \%)$ compared to families $(30.0 \%)$ or teachers (5.9\%) (2013). Whilst girls most often received information from females (e.g. mothers, sisters, friends, and female teachers), a few reported receiving information about menstruation and/or puberty from males (e.g. fathers, uncles, male teachers) (Isguven et al. 2015; Mason et al. 2013).

In some studies, it was unclear on what basis adolescents made judgements about the quality of menstruation information. A study from Nepal that asked schoolgirls whether they felt that they had been properly taught about menstruation reported that $98.0 \%$ of girls felt that they were not properly taught; it is unclear how "properly" was defined by the researchers or understood by the respondents (Adhikari et al. 2007).

\section{Experiences of menstruation or puberty}

The majority of studies (26/44) included at least one outcome measure related to experience of menstruation; experience of puberty was rarely studied (1/44). Dependent upon the sociocultural context, some surveys asked questions about what girls can and cannot do whilst menstruating. A study from Nepal found that $70.7 \%$ of girls reported that girls cannot go to school and that $100 \%$ reported that girls cannot cook whilst menstruating (Adhikari et al. 2007).

Affective aspects of menarche and menstruation were reported. A study from Mexico that grouped girls by age at menarche found significant differences in the reporting of emotional responses to menarche. Compared to early maturers, late maturers were significantly less likely to report being scared, sad, and worried about menarche, and significantly more likely to report being excited or happy (Marván and Alcalá-Herrera 2014). Late maturers were significantly less likely to report that they would have to keep their first period a secret. The authors describe earlier maturers as experiencing a "truncated preparation time to develop the resources and skills needed to cope [with menarche]" (Marván and Alcalá-Herrera 2014).

Negative emotions related to menstruation were associated with issues of menstrual management, particularly around schooling. In some contexts, these emotions were linked to sociocultural norms around menstrual blood. In a study from Kenya it was reported, "Blood is something so secret that it is not recommended anyone to see" (Mason et al. 2013). A menstrual education programme in Bangladesh included a component on "hot or cold food affecting the menstrual cycle". The post-test found the proportion of girls reporting that food temperature did not affect menses increased significantly $(p=0.001)$ (Haque et al. 2014). An intervention in Iran found significant differences in the reporting of emotions (confusing/scared/ uncomfortable/good) about menarche between control and intervention groups (Djalalinia et al. 2012).

\section{Menstrual hygiene management}

Our review includes studies with a wide range of definitions of "good" or "bad" MHM; in some studies any definition of "good" or "bad" was absent. How questions and response categories were phrased raises questions about the ways in which puberty and menstruation research is framed and understood by researchers. Adolescents reported struggling with menstrual hygiene, including obtaining resources for bathing/washing and absorbents. Kenyan schoolgirls said that competing for scarce resources (e.g. soap, water) could cause familial conflict and shame for 
girls unable to conceal menstruation (Mason et al. 2013). In India, girls hid used cloths in damp and dusty places (Shah et al. 2013).

Some studies considered sanitary pads to be any commercially branded or cloth pad, or grouped together sanitary pads and cotton in the analyses (Adhikari et al. 2007; Djalalinia et al. 2012). Other studies separated sanitary pads from cloth pads and reported on separate absorbents (Haque et al. 2014; Shah et al. 2013; Um et al. 2010). Most studies considered new cloth or specialty cloth to be hygienic.

Use of sanitary pads was generally low among studies that separated out sanitary pads from other types of absorbents (e.g. cloths), apart from a Nigerian study that reported $93.8 \%$ of adolescent schoolgirls used sanitary pads (Um et al. 2010). Whilst most girls preferred and valued sanitary pads, the cost made them unaffordable for many (Mason et al. 2013; Shah et al. 2013; Um et al. 2010). Girls rationed pads or used alternative absorbents (Mason et al. 2013). Evidence from India indicates that girls associated alternative and/or reused absorbents with illness and injury (Shah et al. 2013). One study from Kenya discussed how some girls reported obtaining money for sanitary pads in exchange for sex (Mason et al. 2013).

Studies evaluating interventions relating to MHM included both hardware (Phillips-Howard et al. 2016; Shah et al. 2013) and software interventions (Afsari et al. 2017a; Djalalinia et al. 2012; Haque et al. 2014; Kapadia-Kundu et al. 2014; Kheirollahi et al. 2017; Moodi et al. 2013; Nagaraj and Konapur 2016; Sharma et al. 2015; Su and Lindell 2016). Two linked studies combined hardware and software interventions (Hennegan et al. 2016; Montgomery et al. 2016), and assessed the association with school attendance; there was no association between reusable pads and puberty education and school attendance (Hennegan et al. 2016). Both education and provision of reusable sanitary pads were equally as effective in improving school attendance (Montgomery et al. 2016). A hardware intervention in rural India introduced falalin cloths, a low-cost, easily available red material with good absorption capacity. Girls using falalin cloths reported the fewest adverse quality-of-life issues (e.g. absent from school, skin abrasions), whereas girls using old cloths reported the most. At the study's end, $68 \%$ of adolescent girls preferred falalin cloths, whilst $32 \%$ of girls preferred sanitary pads (Shah et al. 2013); none preferred old cloths.

Haque et al. (Haque et al. 2014) delivered culturally adapted menstrual education, including menstrual hygiene demonstrations, to schoolgirls. They reported significant $(\mathrm{p}<0.05)$ improvement in use of sanitary pads, the frequency of changing pads/cloths, drying the absorbent outside in sunlight, disposal of the absorbent by burial/ burning/binning, and cleaning genitalia (Haque et al. 2014). In Iran, researchers randomly allocated students to one of three groups (control, trained by parents, trained by school) for a training programme. The trained groups bathed more frequently during menstruation than the control group and were more likely to use sanitary pads or cotton as a menstrual absorbent. This community-based educational intervention reported benefiting from including parents and teachers, although the study reports many limitations, including missing data values (Djalalinia et al. 2012). The education program implemented by Sharma et al. (2015) among Indian schoolgirls found a significant $(p=0.01)$ impact on the frequency of changing sanitary pads, genital cleaning, and reuse of cloths after washing. However, the study failed to include significant details about the study design, intervention, and outcomes.

\section{Discussion}

Early adolescence represents a critical transitional period when gender norms can act in multiple ways to impact on adolescents' lives (Igras et al. 2014). An over-arching theme emerges from our review: young adolescent girls in LMICs are under-prepared for puberty and menstruation.

Our review shows that puberty and menarche are inadequately researched and understood, in particular evidence relating to the experiences of young adolescents. The evidence base lags behind the rise in interest from practitioners in education and/or health (Adams et al. 2009; Haver and Long n.d.; House et al. 2012; UNESCO 2014) as well as the development (and evaluation) of interventions dealing with puberty and menstruation and its management such as Growing Up Smart (IRH 2015a; Rwanda: IRH 2015b); CycleSmart (Guatemala and Rwanda: IRH 2013a, b) and Choices (Nepal: IRH 2011). The volume of evidence is out of step with the scale of the issues associated with puberty, menstruation and its management.

The paucity of evidence on younger adolescents reflects, in part, the difficulties of researching this group. Many nationally representative surveys (e.g. DHS) include unmarried 15-19-year-olds in their sample; evidence is much less routinely collected from 10 to 14-year-olds. Evidence gaps may also reflect sociocultural contexts in which research with pre-menarcheal girls is constrained, especially across generations. Qualitative evidence underscores the proscribed nature of talking about puberty and menstruation, even among close relatives or friends. Whilst mothers were the main source of information reported in our scoping review, mothers themselves may lack sufficient, accurate knowledge of puberty or menstruation.

The most common interventions were software interventions that introduced or changed girls' education about puberty and/or menstruation. The quality of intervention studies was low, with several studies providing insufficient 
detail on study design, intervention, evaluation, and results, thus hindering efforts to draw firm conclusions and replicate the interventions. No studies examined the impact of intervention duration or dosage. Evidence about sociocultural norms, including restrictions, relating to menstruation is critical to inform the design and content of appropriate interventions (House et al. 2012).

Some studies included evidence from people other than adolescent girls (e.g. teachers, mothers, fathers); adolescent boys were rarely included. The roles (colleague, peer, brother, father) played by men and boys in supporting girls and women in their MHM remain under-appreciated (House et al. 2012). Studies that also included adolescent boys usually did not ask them questions about menstruation; these questions were often only asked of girls.

Currently, the volume and quality of evidence does not align with the scale of the issues associated with puberty, menstruation and its management. Our scoping review suggests multiple agendas for future evidence and research, all framed by a need for evidence that is socioculturally and contextually relevant. The high proportion of school-based studies means we know very little about young out-ofschool adolescents; some girls might be out of school for menstruation-related reasons. Evidence from non-school sample recruitment, including purposive recruitment of outof-school adolescent girls, is needed. Better understanding the roles played by others-adolescent boys, parents, peers, teachers-and their understandings of puberty and menstruation would better contextualise girls' experiences. Research would benefit from the production and use of consistent standards, grounded in evidence, of what is "acceptable" or "appropriate" knowledge. A majority of evidence does not specify or define key concepts related to knowledge and experience of puberty and/or menstruation. We still know very little about how adolescent girls implement MHM practices. In LMICs, effective MHM may require girls to compete for scarce resources (e.g. soap, water, money for proper absorbents), and factors such as socioeconomic status are likely to influence girls' agency. Pubertal and menstrual stigma-their construction and consequences across girls' lives (e.g. education)—remain poorly understood, as do the interventions to overcome them. Little is known about the impact of timing of puberty or menstruation interventions and education. There have been few attempts to directly compare "hardware" and "software" interventions, meaning that we do not know whether and how providing girls with physical supplies (e. g. pads) versus information (e.g. how to manage menstruation) leads to better outcomes. Finally, girls' views and voices are rare in the current evidence base. Future research needs to facilitate girls' meaningful participation in setting agendas and shaping interventions in order to capture the complexity of girls' experiences.
Acknowledgements This research was supported by the Gender and Adolescence: Global Evidence (GAGE) programme which is funded by UK Aid from the UK Department for International Development (DFID).

\section{Compliance with ethical standards}

Conflict of interest The authors declare that they have no conflict of interest.

Open Access This article is distributed under the terms of the Creative Commons Attribution 4.0 International License (http://creative commons.org/licenses/by/4.0/), which permits unrestricted use, distribution, and reproduction in any medium, provided you give appropriate credit to the original author(s) and the source, provide a link to the Creative Commons license, and indicate if changes were made.

\section{References}

Adams J, Bartram J, Chartier Y, Sims J (2009) Water, sanitation and hygiene standards for schools in low-cost settings. WHO, Geneva

Adhikari P, Kadel B, Dhungel SI, Mandal A (2007) Knowledge and practice regarding menstrual hygiene in rural adolescent girls of Nepal. Kathmandu Univ Med J (KUMJ) 5:382-386

Afsari A, Mirghafourvand M, Valizadeh S, Abbasnezhadeh M, Galshi M, Fatahi S (2017a) The effects of educating mothers and girls on the girls' attitudes toward puberty health: a randomized controlled trial. Int J Adolesc Med Health. https://doi.org/10. 1515/ijamh-2015-0043

Afsari A, Valizadeh S, Fatahi S, Abbasnezhad M, Assdollahi M (2017b) Predictors of knowledge and practice of girl students about puberty health. Int J Pediatr 5(7): 5229-5236

Alam MU, Luby SP, Halder AK, Islam K, Opel A, Shoab AK, Ghosh PK, Rahman M, Mahon T, Unicomb L (2017) Menstrual hygiene management among Bangladeshi adolescent schoolgirls and risk factors affecting school absence: results from a cross-sectional survey. BMJ Open 7(7):e015508

Al Omari O, Abdel Razeq NM, Fooladi MM (2016) Experience of Menarche among Jordanian adolescent girls: an interpretive phenomenological analysis. J Pediatr Adolesc Gynecol 29:246251. https://doi.org/10.1016/j.jpag.2015.09.005

Agofure O, Iyama M (2016) Knowledge of puberty, sexually transmitted infections, and sexual behavior among very young female adolescent students' 10-14 years in Agbor Metropolis, Nigeria. Nigerian J Health Sci 16(1):27

Anbumalar A, Sasirekha B (2016) Menstrual health problems and menstrual management of adolescent girls. Int J Nurs Educ Res 4:411-412

Arksey H, O'Malley L (2005) Scoping studies: towards a methodological framework. Int J Soc Res Methodol 8:19-32. https://doi. org/10.1080/1364557032000119616

Bawono AG (2017) Relation between physical change understanding and the teenage anxiety when entering puberty stage at SMPN 3. Klaten Jurnal Ilmu Kesehatan STIKES Duta Gama Klaten 9

Bello BM, Fatusi AO, Adepoju OE, Maina BW, Kabiru CW, Sommer M, Mmari K (2017) Adolescent and parental reactions to puberty in Nigeria and Kenya: a cross-cultural and intergenerational comparison. J Adolesc Health 61:S35-S41

Bosch AM, Hutter I, van Ginneken JK (2008) Perceptions of adolescents and their mothers on reproductive and sexual 
development in Matlab, Bangladesh. Int J Adolesc Med Health 20:329-342

Chandra-Mouli V, Patel SV (2017) Mapping the knowledge and understanding of menarche, menstrual hygiene and menstrual health among adolescent girls in low-and middle-income countries. Reprod Health 14:30

Chothe V et al (2014) Students' perceptions and doubts about menstruation in developing countries: a case study from India. Health Promot Pract 15:319-326. https://doi.org/10.1177/ 1524839914525175

Dabade KJ, Dabade SK (2017) Comparative study of awareness and practices regarding menstrual hygiene among adolescent girls residing in urban and rural area. Int J Commun Med Publ Health 4(4):1284-1288

Davis K, Drey N, Gould D (2009) What are scoping studies? A review of the nursing literature. Int J Nurs Stud 46:1386-1400

Djalalinia S, Tehrani FR, Afzali HM, Hejazi F, Peykari N (2012) Parents or school health trainers, which of them is appropriate for menstrual health education? Int J Prev Med 3:622-627

Dolan CS, Ryus CR, Dopson S, Montgomery P, Scott L (2014) A blind spot in girls' education: menarche and its webs of exclusion in Ghana. J Int Dev 26:643-657. https://doi.org/10. 1002/jid.2917

EPHPP (2010) Quality assessment tool for quantitative studies. Effective Public Health Practice Project, Hamilton. https://merst. ca/ephpp/. Accessed 21 Mar 2017

Fazio, JC, Irving M, Marquez F, Deissinger M, Tomedi A, Schmitt C (2017) The effect of sanitary pads and menstrual symptom management on school performance of adolescent girls in rural Kenya: A cluster randomized trial. Ann Glob Health 83(1):100. https://doi.org/10.5334/j.aogh.2017.03.222

Grant MJ, Booth A (2009) A typology of reviews: an analysis of 14 review types and associated methodologies. Health Inf Libr J 26:91-108. https://doi.org/10.1111/j.1471-1842.2009.00848.x

Haque SE, Rahman M, Itsuko K, Mutahara M, Sakisaka K (2014) The effect of a school-based educational intervention on menstrual health: an intervention study among adolescent girls in Bangladesh. BMJ Open 4:e004607. https://doi.org/10.1136/ bmjopen-2013-004607

Haver J, Long JL (n.d.) Menstrual hygiene management operational guidelines. Save the Children, London

Hennegan J, Montgomery P (2016) Do menstrual hygiene management interventions improve education and psychosocial outcomes for women and girls in low and middle income countries? A systematic review. PLoS ONE 11:e0146985. https://doi.org/ 10.1371/journal.pone.0146985

Hennegan J, Dolan C, Wu M, Scott L, Montgomery P (2016) Schoolgirls' experience and appraisal of menstrual absorbents in rural Uganda: a cross-sectional evaluation of reusable sanitary pads. Reprod Health 13:143. https://doi.org/10.1186/s12978016-0260-7

Hossain S, Sharma P, Sen V (2017) A Study of the knowledge and practice regarding menstrual hygiene in rural adolescent school going girls in an Indian Cosmopolitan city. J Pharm Pract Commun Med 3(3):185-187

House S, Mahon T, Cavill S (2012) Menstrual hygiene matters: a resource for improving menstrual hygiene around the world. WaterAid, London

Hyang-Mi J, Kim K-K, 김이순 (2006) Related factors affecting menstrual attitudes among high school girls. J Korean Data Anal Soc 8:1779-1791

Igras SM, Macieira M, Murphy E, Lundgren R (2014) Investing in very young adolescents' sexual and reproductive health. Glob Public Health 9:555-569. https://doi.org/10.1080/17441692.2014.908230

Iliyasu Z, Aliyu MH, Abubakar IS, Galadanci HS (2012) Sexual and reproductive health communication between mothers and their adolescent daughters in northern Nigeria. Health Care Women Int 33:138-152. https://doi.org/10.1080/07399332.2011.562996

Institute for Reproductive Health (2011) Utilizing participatory data collection methods to evaluate programs for very young adolescents: an evaluation of save the children's choices curriculum in Siraha, Nepal. Institute for Reproductive Health, Georgetown University for the U.S. Agency for International Development (USAID), Washington, DC

Institute for Reproductive Health (2013a) Developing the CycleSmart ${ }^{\mathrm{TM}}$ Kit: Guatemala Country Report exploring the use of CycleBeads ${ }^{\circledR}$ and an informational brochure to increase fertility awareness among youth. The Institute for Reproductive Health, Georgetown University for the U.S. Agency for International Development (USAID), Washington, DC

Institute for Reproductive Health (2013b) Rwanda CycleSmart Study. Institute for Reproductive Health, Georgetown University for the U.S. Agency for International Development (USAID), Washington, DC

Institute for Reproductive Health (2015a) Grow Up Smart Endline Study Report. Institute of Reproductive Health, Georgetown University, Washington, DC

Institute for Reproductive Health (2015b) Grow Up Smart: Baseline study report. The Institute for Reproductive Health, Georgetown University, Washington, DC

Isguven P, Yoruk G, Cizmecioglu FM (2015) Educational needs of adolescents regarding normal puberty and menstrual patterns. J Clin Res Pediatr Endocrinol 7:312-322. https://doi.org/10. 4274/jcrpe. 2144

Jena P, Andalib S, Khuntia S, Mishra A (2017a) Spectrum of menstrual disorder and health conciousness of adolescent school going girls: A comparative study between the extremes of two socio-economic group. Indian J Obstet Gynecol Res 4(3):235239

Jena P, Agasti N, Andalib S, Khandelwal K (2017b) Menstrual problems and health awareness of tribal adolescent schoolgirls of Odisha-A cross-sectional study. J Evol Med Dent Sci 6 (51):3917-3921

Kapadia-Kundu N, Storey D, Safi B, Trivedi G, Tupe R, Narayana G (2014) Seeds of prevention: the impact on health behaviors of young adolescent girls in Uttar Pradesh, India, a cluster randomized control trial. Soc Sci Med 120:169-179. https:// doi.org/10.1016/j.socscimed.2014.09.002

Khalil H, Peters M, Godfrey CM, McInerney P, Soares CB, Parker D (2016) An evidence-based approach to scoping reviews. Worldviews Evid Based Nurs 13:118-123

Kheirollahi F, Rahimi Z, Arsang-Jang S, Sharifirad G, Sarraf P, Gharlipour Z (2017) Puberty health status among adolescent girls: a model-based educational program. Int J Pediatr Mashhad 5:5369-5378. https://doi.org/10.22038/ijp.2017.23174.1950

Kirk J, Sommer M (2006) Menstruation and body awareness: linking girls' health with girls' education. Royal Tropical Institute (KIT), Amsterdam

Kumar D, Goel NK, Sharma MK, Kaur G (2016) Menstrual problems of school going unmarried adolescent girls and their treatment seeking behavior in Chandigarh, India. Int J Commun Med Publ Health 3(11):3106-3116

Marván ML, Alcalá-Herrera V (2014) Age at menarche, reactions to menarche and attitudes towards menstruation among Mexican adolescent girls. J Pediatr Adolesc Gynecol 27:61-66. https:// doi.org/10.1016/j.jpag.2013.06.021

Marván ML, Molina-Abolnik M (2012) Mexican adolescents' experience of menarche and attitudes toward menstruation: role of communication between mothers and daughters. J Pediatr Adolesc Gynecol 25:358-363. https://doi.org/10.1016/j.jpag. 2012.05.003 
Mason L et al (2013) 'We keep it secret so no one should know'-a qualitative study to explore young schoolgirls attitudes and experiences with menstruation in rural western Kenya. PLoS ONE 8:e79132. https://doi.org/10.1371/journal.pone.0079132

MDWS (2015) Menstrual Hygiene Management National Guidelines. Ministry of Drinking Water and Sanitation, India. https://mdws. gov.in/menstrual-hygiene-management-national-guidelinesdecember-2015. Accessed 02 Jan 2018

Mishra SK, Dasgupta D, Ray S (2017) A study on the relationship of sociocultural characteristics, menstrual hygiene practices and gynaecological problems among adolescent girls in Eastern India. Int J Adolesc Med Health 29(5):20150111

Mmari K et al (2016) "Yea, I've grown; I can't go out anymore": perceived risks for girls and boys entering adolescence. Paper presented at the Population Association of America, Washington, DC. $01 / 04 / 2016$

Montgomery P, Hennegan J, Dolan C, Wu M, Steinfield L, Scott L (2016) Menstruation and the cycle of poverty: a cluster quasirandomised control trial of sanitary pad and puberty education provision in Uganda. PLoS ONE 11:e0166122. https://doi.org/ 10.1371/journal.pone.0166122

Moodi M, Zamanipour N, Sharifirad G-R, Shahnazi H (2013) Evaluating puberty health program effect on knowledge increase among female intermediate and high school students in Birjand, Iran. J Educ Health Promot 2:57-57. https://doi.org/10.4103/ 2277-9531.120851

Mumtaz S, Ansari SK (2016) Psychology of beliefs and practices relating to menstrual hygiene of adolescent girls in rural, Islamabad, Pakistan. Imperial J Interdisc Res 2(7):670-677

Nagaraj C, Konapur KS (2016) Effect of health education on awareness and practices related to menstruation among rural adolescent school girls in Bengaluru, Karnataka. Int J 2:19

Pham MT, Rajić A, Greig JD, Sargeant JM, Papadopoulos A, McEwen SA (2014) A scoping review of scoping reviews: advancing the approach and enhancing the consistency. Res Synth Methods 5:371-385

Phillips-Howard PA et al (2016) Menstrual cups and sanitary pads to reduce school attrition, and sexually transmitted and reproductive tract infections: a cluster randomised controlled feasibility study in rural Western Kenya. BMJ Open 6:e013229. https://doi. org/10.1136/bmjopen-2016-013229

Pratibha S, Nawaz AS, Kumar A (2016) Impact of Menstrual Practices on the Health of Adolescent Girls and the Challenges Faced in Menstrual Hygiene Management at Schools. Nat J Commun Med 7(8):667-671

PRISMA (2017) Preferred reporting items for systematic reviews and meta-analyses. http://www.prisma-statement.org/. Accessed $21 / 03 / 2017$

Ramachandra K, Gilyaru S, Eregowda A, Yathiraja S (2016) A study on knowledge and practices regarding menstrual hygiene among urban adolescent girls. Int J Contemp Pediatr 3(1):142-145

Saghi S, Mirghafourvand M, Alizadeh Charandabi SM, Nabighadim A, Seidi S, Rahmani A (2016) Knowledge and attitude about pubertal health and their socio-demographic predictors in Iranian adolescents. Int J Adolesc Med Health 28:397-405. https://doi. org/10.1515/ijamh-2015-0016

Shah SP, Nair R, Shah PP, Modi DK, Desai SA, Desai L (2013) Improving quality of life with new menstrual hygiene practices among adolescent tribal girls in rural Gujarat, India. Reprod Health Matters 21:205-213. https://doi.org/10.1016/s0968-8080 (13)41691-9

Shaikh BT, Rahim ST (2006) Assessing knowledge, exploring needs: a reproductive health survey of adolescents and young adults in Pakistan. Eur J Contracept Reprod Health Care 11:132-137. https://doi.org/10.1080/13625180500389463
Sharma I, Moktan E (2017) Assessing the level of knowledge and practice of menstrual hygiene among adolescent school girls in Siraha district of Nepal: A cross sectional study. Asian J Multi Stud 5(10):135-142

Sharma R, Negi S, Kunj D, Sharma V, Vardha (2015) Menstrual hygiene among adolescent girls. Indian J Community Health $27: 376-380$

Sharma S, Choudhary S, Saluja N, Gaur D, Kumari S, Pandey S, Hisar H (2016) Knowledge and practices about menstrual hygiene among school adolescent girls in Agroha village of Haryana. Age 64:42-47

Shoor P (2017) A study of knowledge, attitude, and practices of menstrual health among adolescent school girls in urban field practice area of medical college, Tumkur. Indian J Health Sci Biomed Res (KLEU) 10(3):249-255

Solnes Miltenburg A, Roggeveen Y, Mv Elteren, Shields L, Bunders J, Roosmalen J, Stekelenburg J (2013) A protocol for a systematic review of birth preparedness and complication readiness programs. Syst Rev 2:11. https://doi.org/10.1186/ 2046-4053-2-11

Sommer M, Ackatia-Armah N, Connolly S, Smiles D (2015) A comparison of the menstruation and education experiences of girls in Tanzania, Ghana, Cambodia and Ethiopia. Compare $\mathbf{J}$ Comp Int Educ 45:589-609. https://doi.org/10.1080/03057925. 2013.871399

Sridhar D, Gauthami N (2017) Menstrual health status and cultural practices of tribal adolescent girls. Int J Commun Med Publ Health 4 (11):4120-4124

Su JJ, Lindell D (2016) Promoting the menstrual health of adolescent girls in China. Nurs Health Sci 18:481-487. https://doi.org/10. 1111/nhs. 12295

Sumpter C, Torondel B (2013) A systematic review of the health and social effects of menstrual hygiene management. PLoS ONE 8: e62004. https://doi.org/10.1371/journal.pone.0062004

Tasnim S, Rahman A, Ara I (2009) Talking about sexuality at secondary schools of periurban area of Dhaka city. Int J Adolesc Med Health 21:601-608

The Joanna Briggs Institute (2015) Joanna Briggs Institute Reviewers' Manual: 2015 edition/supplement. The Joanna Briggs Institute, Adelaide

Um L, Yusuf NW, Musa AB (2010) Menstruation and menstrual hygiene amongst adolescent school girls in Kano, Northwestern Nigeria. Afr J Reprod Health 14:201-207

UNESCO (2014) Puberty education and menstrual hygiene management, vol 9. UNESCO, Paris

Valizadeh S, Assdollahi M, Mirghafourvand M, Afsari A (2017) Educating mothers and girls about knowledge and practices toward puberty hygiene in Tabriz, Iran: a randomized controlled clinical trial. Iran Red Crescent Med J 19:10. https://doi.org/10. 5812/ircmj.28593

van Eijk AM, Sivakami M, Thakkar MB, Bauman A, Laserson KF, Coates S, Phillips-Howard PA (2016) Menstrual hygiene management among adolescent girls in India: a systematic review and meta-analysis. BMJ Open 6:e010290. https://doi.org/10. 1136/bmjopen-2015-010290

Walsh D, Downe S (2006) Appraising the quality of qualitative research. Midwifery 22:108-119

WHO and UNICEF (2013) Progress on sanitation and drinking water -2013 update. WHO, Geneva

World Bank (2016) World Bank Country and Lending Groups. https://datahelpdesk.worldbank.org/knowledgebase/articles/ 906519. Accessed 1 June 2016

Publisher's Note Springer Nature remains neutral with regard to jurisdictional claims in published maps and institutional affiliations. 